\title{
Antiproliferative factor decreases Akt phosphorylation and alters gene expression via CKAP4 in T24 bladder carcinoma cells
}

\author{
Hanief M Shahjee ${ }^{1}$, Kristopher R Koch¹, Li Guo ${ }^{1}$, Chen-Ou Zhang ${ }^{1}$, Susan K Keay ${ }^{1,2^{*}}$
}

\begin{abstract}
Background: Urinary bladder cancer is a common malignancy worldwide, and outcomes for patients with advanced bladder cancer remain poor. Antiproliferative factor (APF) is a potent glycopeptide inhibitor of epithelial cell proliferation that was discovered in the urine of patients with interstitial cystitis, a disorder with bladder epithelial thinning and ulceration. APF mediates its antiproliferative activity in primary normal bladder epithelial cells via cytoskeletal associated protein 4 (CKAP4). Because synthetic asialo-APF (as-APF) has also been shown to inhibit T24 bladder cancer cell proliferation at nanomolar concentrations in vitro, and because the peptide segment of APF is $100 \%$ homologous to part of frizzled 8 , we determined whether CKAP4 mediates as-APF inhibition of proliferation and/or downstream Wnt/frizzled signaling events in T24 cells.
\end{abstract}

Methods: T24 cells were transfected with double-stranded siRNAs against CKAP4 and treated with synthetic as-APF or inactive control peptide; cells that did not undergo electroporation and cells transfected with non-target (scrambled) double-stranded siRNA served as negative controls. Cell proliferation was determined by ${ }^{3} \mathrm{H}$-thymidine incorporation. Expression of Akt, glycogen synthase kinase $3 \beta$ (GSK3 $\beta$ ), $\beta$-catenin, p53, and matrix metalloproteinase 2 (MMP2) mRNA was determined by quantitative reverse transcriptase polymerase chain reaction (qRT-PCR). Akt,

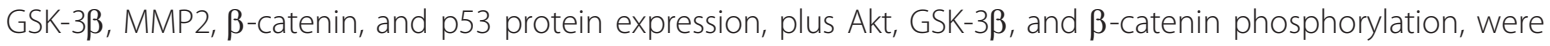
determined by Western blot.

Results: T24 cell proliferation, MMP2 expression, Akt ser473 and thr308 phosphorylation, GSK3 $\beta$ tyr216 phosphorylation, and $\beta$-catenin ser45/thr41 phosphorylation were all decreased by APF, whereas p53 expression, and $\beta$-catenin ser33,37/thr41 phosphorylation, were increased by APF treatment in non-electroporated and nontarget siRNA-transfected cells. Neither mRNA nor total protein expression of Akt, GSK3 3 , or $\beta$-catenin changed in response to APF in these cells. In addition, the changes in cell proliferation, MMP2/p53 mRNA and protein expression, and Akt/GSK3 $\beta / \beta$-catenin phosphorylation in response to APF treatment were all specifically abrogated following CKAP4 siRNA knockdown.

Conclusions: Synthetic as-APF inhibits cell proliferation in T24 bladder carcinoma cells via the CKAP4 receptor. The mechanism for this inhibition involves regulating phosphorylation of specific cell signaling molecules (Akt, GSK3 $\beta$, and $\beta$-catenin) plus mRNA and protein expression of p53 and MMP2.

\section{Background}

Bladder cancer is the second most common genitourinary malignancy and the fourth most common malignancy in men in the United States, causing over 12,000 deaths annually [1]. Although seventy percent of cases

\footnotetext{
* Correspondence: skeay@medicine.umaryland.edu

'Division of Infectious Diseases, Department of Medicine, University of

Maryland School of Medicine, Baltimore, Maryland, USA

Full list of author information is available at the end of the article
}

are diagnosed in the superficial stage, up to $30 \%$ can present with or develop muscle-invasive disease, and long term outcomes for patients with advanced bladder cancer remain poor $[2,3]$. Additional treatments that prevent or control the progression of bladder carcinoma are therefore sorely needed.

Altered expression of certain genes commonly found in human carcinomas are also found in bladder cancer, including decreased expression of E-cadherin [4-8] and 
the tumor suppressors p53 and p21 [9-11], with increased expression of heparin-binding epidermal growth factor-like growth factor (HB-EGF) [12]. Of these abnormalities, decreased E-cadherin and increased HB-EGF expression appear to be particularly closely associated with increased tumor progression, cell proliferation, and/or metastasis [5-8,12-15]. Therapies aimed at controlling the aberrant expression of genes associated with tumor progression and metastasis in bladder carcinoma cells may be helpful for controlling disease.

Our laboratory previously discovered a natural antiproliferative factor (APF) [16-18] that profoundly inhibits bladder epithelial cell proliferation $[19,20]$, upregulates E-cadherin [21], p53 and p21 [22] expression, and inhibits the production of other cell proteins including HB-EGF $[17,20,21,23]$. APF is secreted specifically by bladder epithelial cells from patients with interstitial cystitis (IC), a chronic bladder disorder characterized by bladder epithelial thinning and/or ulceration [24-26]. APF is a low molecular weight frizzled 8-related glycopeptide that inhibits both normal and IC bladder epithelial cell proliferation via cytoskeleton associated protein 4 (CKAP4, also known as CLIMP-63 and ERGIC-63) [27], a type II transmembrane receptor [28] whose palmitoylation appears to be required for mediating APF activity in HeLa cells [29]. Synthetic asialo-APF (as-APF) inhibits T24 bladder carcinoma cell proliferation in vitro at low (nanomolar) concentrations similar to those required for inhibition of normal bladder epithelial cell proliferation [19]. However, neither the role of CKAP4 in regulation of bladder carcinoma cell proliferation, nor its role in mediating APF activity in bladder carcinoma cells, has yet been studied.

Therefore, to better understand the mechanism by which APF regulates T24 bladder carcinoma cell proliferation, we determined the effect of as-APF on the expression or activation of enzymes involved in winglessint (Wnt)/frizzled signaling (including AKR-transforming enzyme (Akt), glycogen synthase kinase-3 beta (GSK3 $\beta$ ), $\beta$-catenin, and matrix metalloprotease 2 (MMP2), as well as the role of CKAP4 in mediating as-APF activity in T24 cells.

\section{Methods \\ Cell Culture}

T24 human urinary bladder cancer cells (ATCC HTB-4) were grown to $60-80 \%$ confluence in McCoy's $5 \mathrm{~A}$ medium (Invitrogen, Carlsbad, CA) containing 10\% heatinactivated fetal bovine serum (FBS), $1 \%$ antibiotic/antimycotic solution, 1\% L-glutamine (all from Sigma, St. Louis, $\mathrm{MO}$ ) and 2.2 grams/L sodium bicarbonate (Invitrogen), in a $37^{\circ} \mathrm{C} / 5 \% \mathrm{CO}_{2}$ atmosphere.

\section{siRNA Transfection}

Double-stranded siRNA corresponding to nucleotides 594-616 of CKAP4 (5'-AACUUUUGAGUCCAUCUU GAGAA-3' sense strand) and a scrambled doublestranded negative control siRNA (5'-AAUUCUGUAUG CUACCUGUAGAA-3' sense strand) were prepared by preincubating single-stranded sense and antisense strands prepared with double A overhangs in serum-free McCoy's $5 \mathrm{~A}$ medium at $37^{\circ} \mathrm{C}$ for 1 hour. T24 human bladder cancer cells were trypsinized for 10 minutes at room temperature, centrifuged in growth medium (as defined above), and the cell pellet was resuspended in serum-free medium at a density of $1 \times 10^{6} \mathrm{cells} / \mathrm{ml}$. Two hundred microliters of the cell suspension were then transferred to a sterile 2-mm cuvette with $14 \mu \mathrm{g}$ of CKAP4 siRNA, scrambled non-target siRNA, or no siRNA, and electroporated at $160 \mathrm{~V} / 500$ microfarad capacitance using a Bio-Rad Gene Pulser Xcell. The cells were then immediately transferred to T75 cell culture flasks (Corning Incorporated, Corning, NY) (for extraction of RNA and protein) or to 96 well tissue culture plates (Corning Incorporated) (for the cell proliferation assay) and incubated in growth medium overnight in a $37^{\circ} \mathrm{C} / 5 \% \mathrm{CO}_{2}$ atmosphere.

\section{APF Treatment (for RNA and Protein Extraction)}

Following overnight incubation in growth medium, transfected T24 human bladder cancer cells were further incubated with serum-free McCoy's 5A medium for the next 24 hours, after which they were treated with $500 \mathrm{nM}$ as-APF or $500 \mathrm{nM}$ inactive nonglycosylated peptide control (both from PolyPeptide Laboratories, Incorporated, San Diego, CA). Cells were then incubated for an additional $48 \mathrm{hrs}$ in a $37^{\circ} \mathrm{C} / 5 \% \mathrm{CO}_{2}$ atmosphere prior to RNA and protein extraction.

\section{RNA Extraction}

Following cell incubation with as-APF or its control peptide/diluent, the culture medium was removed, T24 cells were washed with $1 \times$ PBS, and RNA was extracted using the RNeasy Plus Mini Kit (Qiagen, Valencia, CA) according to the manufacturer's instructions. RNA concentration was measured at $260 \mathrm{nM}$ in a UV/VIS spectrophotometer from Perkin Elmer. Extracted RNA was stored at $-80^{\circ} \mathrm{C}$.

\section{Protein Extraction}

Cell culture medium was removed from duplicate flasks, T24 cells were scraped into ice-cold PBS, and the cell slurry was centrifuged at $4^{\circ} \mathrm{C}$ for 5 minutes at $2000 \mathrm{rpm}$. Supernatant was then removed and the pellet was washed with ice-cold PBS and centrifuged again at $4^{\circ} \mathrm{C}$ for 5 minutes at $2000 \mathrm{rpm}$. This pellet was then resuspended in icecold RIPA buffer (Upstate Cell Signaling Solutions, 
Temecula, CA) containing Complete Protease Inhibitor Cocktail (Roche, Indianapolis, IN) and centrifuged at $14,000 \mathrm{rpm}$ for 15 minutes at $4^{\circ} \mathrm{C}$. Supernatant containing total cell protein was collected and stored at $-80^{\circ} \mathrm{C}$.

\section{${ }^{3} \mathrm{H}$-Thymidine Cell Proliferation Assay}

Cell proliferation was measured by ${ }^{3} \mathrm{H}$-thymidine incorporation into T24 human bladder cancer cells, plating $1.5 \times 10^{3}$ cells/well onto a 96-well cell culture plate (Corning Incorporated), in $150 \mu \mathrm{L} /$ well McCoy's 5A medium containing $10 \%$ heat inactivated FBS, $1 \%$ antibiotic/antimycotic solution, $1 \%$ L-glutamine, and plus 2.2 grams/L sodium bicarbonate. The next day, cell growth medium was removed and replaced with $100 \mu \mathrm{l}$ serum-free McCoy's medium. On the third day, synthetic as-APF was resuspended in acetonitrile/distilled water $(1: 1)$ and applied to the cells in serum-free McCoy's medium at varying concentrations; cell controls received acetonitrile/distilled water diluted in serum-free McCoy's medium (same final concentration of diluent). Cells were then incubated at $37^{\circ} \mathrm{C}$ in a $5 \%$ $\mathrm{CO}_{2}$ atmosphere for an additional 48 hours, after which they were labeled with $1 \mu \mathrm{Ci}$ per well ${ }^{3} \mathrm{H}$-thymidine at $37^{\circ} \mathrm{C}$ in a $5 \% \mathrm{CO}_{2}$ atmosphere for 4 hours. The cells were then treated with trypsin-EDTA (Invitrogen), insoluble cell contents harvested and methanol-fixed onto glass fiber filter paper, and the amount of radioactivity incorporated determined using a Beckman scintillation counter. Significant inhibition of ${ }^{3} \mathrm{H}$-thymidine incorporation was defined as a decrease in $\mathrm{cpm}$ of $>2 \mathrm{SD}$ from the mean of control cells for each plate.

\section{Real-time qRT-PCR}

Gene expression was determined using $\mathrm{SYBR}^{\circ}$ Green based real-time RT-PCR, QuantiTect ${ }^{\circ}$ primers and reagents (Qiagen) and a Roche 480 LightCycler. Samples were tested in triplicate runs, and specific mRNA levels quantified and compared to mRNA levels for $\beta$-actin or GAPDH using Roche LC480 real-time PCR analysis software (version 1.5.0). Predetermined optimal concentrations of RNA were used for each set of primers. p53 (QT00060235), Akt (QT00085379), GSK3ß (QT000 57134), $\beta$-catenin (QT00077882), MMP2 (QT00088396), GAPDH (QT01192646), and $\beta$-actin (QT1680476) primer sets were obtained from Qiagen. p53 served as a standard control for APF activity, while GAPDH and $\beta$-actin served as standard controls for the qRT-PCR procedure.

\section{SDS Polyacrylamide Gel Electrophoresis and Western Blot Assay}

Specific protein expression or phosphorylation was determined by Western blot. Protein concentration was measured using a Folin reagent-based protein assay kit (Bio-Rad, Hercules, CA). Solubilized cell proteins were incubated for $10 \mathrm{~min}$ at $70^{\circ} \mathrm{C}$ in sample reducing buffer, each lane was loaded with $30 \mu \mathrm{g}$ of protein, and proteins were separated by electrophoresis using 4-12\% NuPAGE NOVEX BisTris polyacrylamide gels (Invitrogen) in MOPS/SDS running buffer (Invitrogen), according to the manufacturer's instructions. Proteins were then transferred to nitrocellulose membranes (Invitrogen) according to the NuPAGE gel manufacturer's protocol for Western transfer ( $30 \mathrm{~V}$ constant voltage for $1 \mathrm{~h}$ ). Following protein transfer, the nitrocellulose membranes were blocked with $5 \%$ nonfat dry milk in TBS-T buffer (Tris-buffered saline, $\mathrm{pH} 7.4$, with $0.1 \%$ Tween 20 ) and incubated overnight at $4^{\circ}$ $\mathrm{C}$ in TBS-T buffer containing mouse monoclonal antiCKAP4 ("anti-CLIMP-63," clone G1/296) (Alexis Biochemical, Plymouth Meeting, PA), anti-p53 (Calbiochem, San Diego, CA), anti-GSK3 $\beta$ (BD Biosciences, San Jose, CA), anti-phosphoGSK3 $\beta$ (tyr 216) (BD Biosciences), or anti- $\beta$ actin (Sigma) antibodies; or rabbit polyclonal anti-MMP2, anti-Akt, anti-phosphoAkt (ser473/thr308), anti-phosphoGSK3 $\beta$ (ser9), anti- $\beta$-catenin, anti-phospho $\beta$ catenin (ser 33,37/thr 41), or anti-phospho $\beta$-catenin (ser 45/thr 41) (all obtained from Cell Signaling Technology, Danvers, MA). When more than one antibody was used for binding to proteins on a single membrane, the membrane was stripped between antibody incubations using Restore PLUS Western blot stripping buffer (Pierce, Rockford, IL) according to the manufacturer's instructions. The membranes were subsequently washed three times with TBS-T, incubated with horseradish peroxidase-conjugated goat anti-mouse or goat anti-rabbit IgG secondary antibodies (Santa Cruz Biotechnology, Santa Cruz, CA) for $1 \mathrm{~h}$ at room temperature, and developed with ECL chemiluminescence Reagent (Amersham Biosciences, Piscataway, NJ). p53 expression served as a positive control for APF activity; $\beta$-actin expression served as a standard control for the Western blot procedure.

\section{Statistical Analysis}

Significant inhibition of ${ }^{3} \mathrm{H}$-thymidine incorporation was defined as a mean decrease in cpm of \pm 2 SD from the mean of control cells for each plate. Crossover point analysis was performed for qRT-PCR data, and mRNA copy number for each gene was quantified relative to $\beta$-actin; this value is expressed as mean \pm standard error of the mean (SEM) for duplicate runs performed on three separate occasions. The significance of the difference between mean values was determined by an analysis of variance with $\mathrm{p}<.05$ considered significant.

\section{Results}

siRNA knockdown of CKAP4 expression inhibits APF antiproliferative activity in T24 bladder carcinoma cells

To determine whether APF activity was mediated by CKAP4 in T24 cells, expression of this receptor was 
knocked down by double-stranded siRNA transfection via electroporation. Non-target (scrambled) siRNA was used to confirm the specificity of CKAP4 knockdown, and untreated cells served as negative controls for the electroporation procedure. Decreased CKAP4 protein expression following CKAP4 siRNA transfection was confirmed by Western blot (Figure 1A). As shown in Figure 1B, dose-dependent inhibition of T24 cell proliferation by submicromolar concentrations of as-APF was specifically and significantly decreased following CKAP4 knockdown $(\mathrm{p}<.001$ for comparison of CKAP siRNAtreated cells compared to both controls at concentrations $\geq 1.25 \mathrm{nM}$ ), indicating the importance of this receptor for mediating APF antiproliferative activity in T24 bladder carcinoma cells.

\section{APF increases p53 tumor suppressor gene expression via CKAP4 in T24 cells}

HPLC-purified native APF was previously shown to significantly decrease cell cycle transit and increase p53 expression in both normal human urothelial cells and T24 bladder carcinoma cells in vitro, while p53 knockdown decreased the antiproliferative effects of APF [22].

A

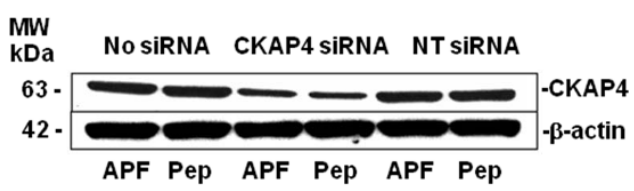

B

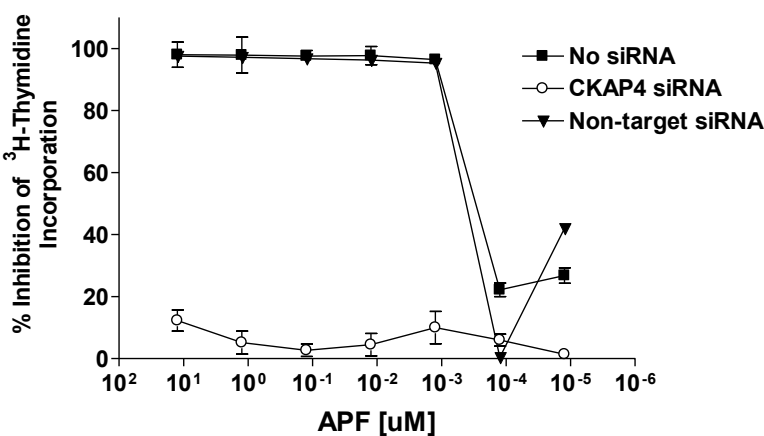

Figure 1 CKAP4 knockdown in T24 cells. A, Western blot analysis of CKAP4 protein expression in cells electroporated in the presence of no siRNA (Lanes 1 and 2), CKAP4 siRNA (Lanes 3 and 4), or scrambled non-target (NT) siRNA (Lanes 5 and 6), and treated with as-APF (APF) or its inactive control peptide (Pep). $\beta$-actin served as a standard control. B, Inhibition of ${ }^{3} \mathrm{H}$-thymidine incorporation by asAPF (APF) in cells electroporated with no siRNA, CKAP4 siRNA, or non-target siRNA. Results are shown as percent inhibition of ${ }^{3} \mathrm{H}-$ thymidine incorporation compared to control cells that did not receive as-APF treatment. Experiment was performed in triplicate twice.
To determine whether CKAP4 mediated APF's stimulation of p53 expression, T24 cells were treated with $500 \mathrm{nM}$ synthetic as-APF or its inactive peptide control and the effects on p53 mRNA and protein expression examined. As shown in Figure 2A, p53 protein expression was increased in APF-treated (as compared to control peptide-treated) nontransfected cells. Similarly, p53 protein expression was also increased in response to APF in cells transfected with non-target siRNA, whereas p53 levels changed less in response to APF following CKAP4 knockdown (Figure 2A). qRT-PCR also showed significantly increased p53 mRNA expression following APF treatment of nontransfected or non-target siRNA-transfected, but not CKAP4 siRNA-transfected, cells (Figure $2 \mathrm{~B}-\mathrm{D})$ ( $\mathrm{p}<.01$ for both nontransfected and non-target transfected cells, and target gene mRNA relative to $\beta$-actin or GAPDH mRNA; data shown for normalization to $\beta$-actin expression, only). These findings indicate that CKAP4 also mediates the effects of APF on p53 mRNA and protein expression in T24 cells.

\section{Decreased Akt (serine 473 and threonine 308) phosphorylation following APF treatment of T24 cells}

To understand whether Wnt/frizzled signaling might play a role in mediating APF activity in T24 cells, we determined the effect(s) of as-APF treatment on Akt expression and serine/threonine phosphorylation in nontransfected, non-target siRNA-transfected, and CKAP4 siRNA-transfected cells. As shown in Figure 3A, APF treatment caused decreased Akt serine 473 (ser473) and threonine 308 (thr308) phosphorylation in nontransfected and non-target siRNA transfected cells, whereas there was no apparent change in phosphorylation at either site in CKAP4 siRNA-transfected cells. However, APF treatment did not appear to affect total Akt protein (Figure 3A) or Akt mRNA (Figure 3B-D) expression, regardless of transfection status $(p>.05$ for all PCR comparisons, including target gene mRNA relative to $\beta$-actin or GAPDH mRNA; data shown for normalization to $\beta$-actin expression, only). These findings indicate a potential role for inhibition of Akt activation in CKAP4-mediated APF antiproliferative activity.

Decreased GSK3 $\beta$ (tyrosine 216) and $\beta$-catenin (serine 45/ threonine 41) phosphorylation, but increased $\beta$-catenin (serine 33, 37/threonine 41) phosphorylation, in response to APF

In Wnt signaling pathways, Akt phosphorylation/activation stimulates GSK3 $\beta$ serine 9 (ser9) phosphorylation, leading to its inactivation, which in turn inhibits $\beta$-catenin ubiquitination and degradation [30]. We therefore determined whether APF-induced decreased Akt phosphorylation lead to changes in GSK3 $\beta$ and $\beta$-catenin phosphorylation in T24 bladder carcinoma 


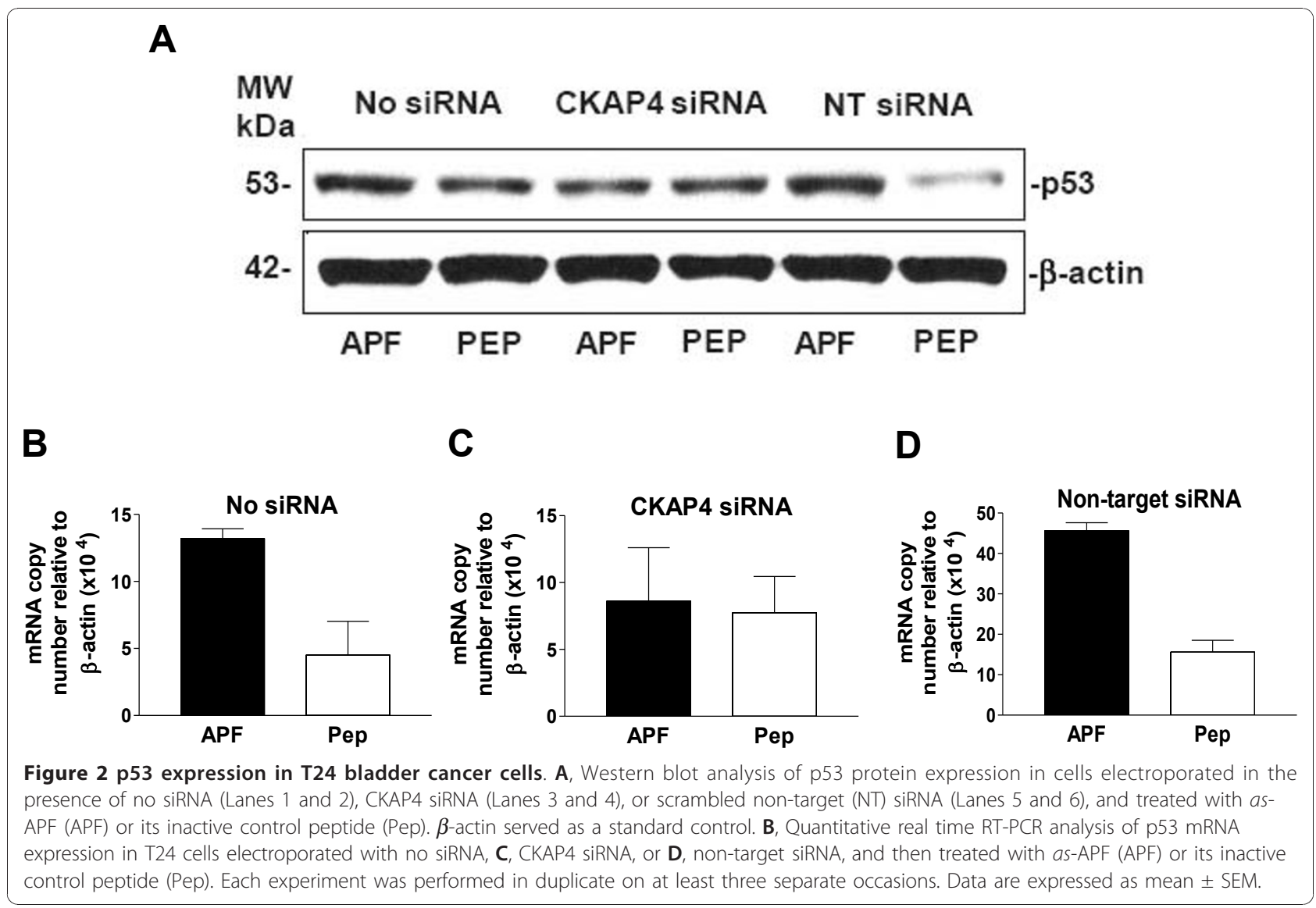

cells. Although GSK3 3 ser9 phosphorylation may have been minimally decreased in APF-treated nontransfected and non-target siRNA-transfected cells response to APF, GSK3 $\beta$ tyrosine 216 (tyr216) phosphorylation was clearly decreased following APF treatment of these same cells (but unchanged in CKAP4 siRNA-transfected cells) (Figure 4A). Again, APF treatment did not appear to affect total GSK3 $\beta$ protein (Figure 4A) or mRNA (Figure 4B-D) expression, regardless of transfection status ( $p>.05$ for all PCR comparisons, including target gene mRNA relative to $\beta$-actin or GAPDH mRNA; data shown for normalization to $\beta$-actin expression, only). These findings indicate that APF induces changes in GSK3 $\beta$ phosphorylation via CKAP4, but further suggest that APF does not mediate its antiproliferative activity in T24 cells merely by inhibiting canonical Wnt/frizzled signaling.

We therefore proceeded to examine the effects of as-APF on $\beta$-catenin and $\beta$-catenin phosphorylation in T24 cells. As shown in Figure $5 \mathrm{~A}$, although subtle increases in $\beta$-catenin phosphorylation were apparent following APF treatment of nontransfected cells when antibodies against phosphoserine 33, 37 and threonine 41 (ser33,37/thr41) sites were used, there was no apparent change in total cell $\beta$-catenin protein. In addition, decreased phosphorylation was apparent following APF treatment when antibodies that recognized phosphoserine 45 (ser45) and phosphothreonine 41 (thr41) were used. Again, these changes in phosphorylation were abrogated by CKAP4 knockdown, and there were no significant differences in $\beta$-catenin mRNA levels regardless of transfection status (Figure 5B-D) ( $p>.05$ for all PCR comparisons, including target gene mRNA relative to $\beta$-actin or GAPDH mRNA; data shown for normalization to $\beta$-actin expression, only). Although these findings suggest subtle changes in $\beta$-catenin phosphorylation in response to APF, they also provide additional evidence that APF may mediate its profound effects on cell proliferation and gene expression via means other than (or in addition to) regulation of canonical Wnt/frizzled signaling pathways.

\section{Downregulation of MMP2 expression by APF in T24} bladder cancer cells via CKAP4

Wnt/frizzled signaling is also known to stimulate cellular production of specific gelatinases including MMP2 [31,32] which has been implicated in HB-EGF activation and cleavage [33] as well as the progression and/or occurrence of various cancers including bladder cancer [34-37]. As the expression of MMP2 is also known to 


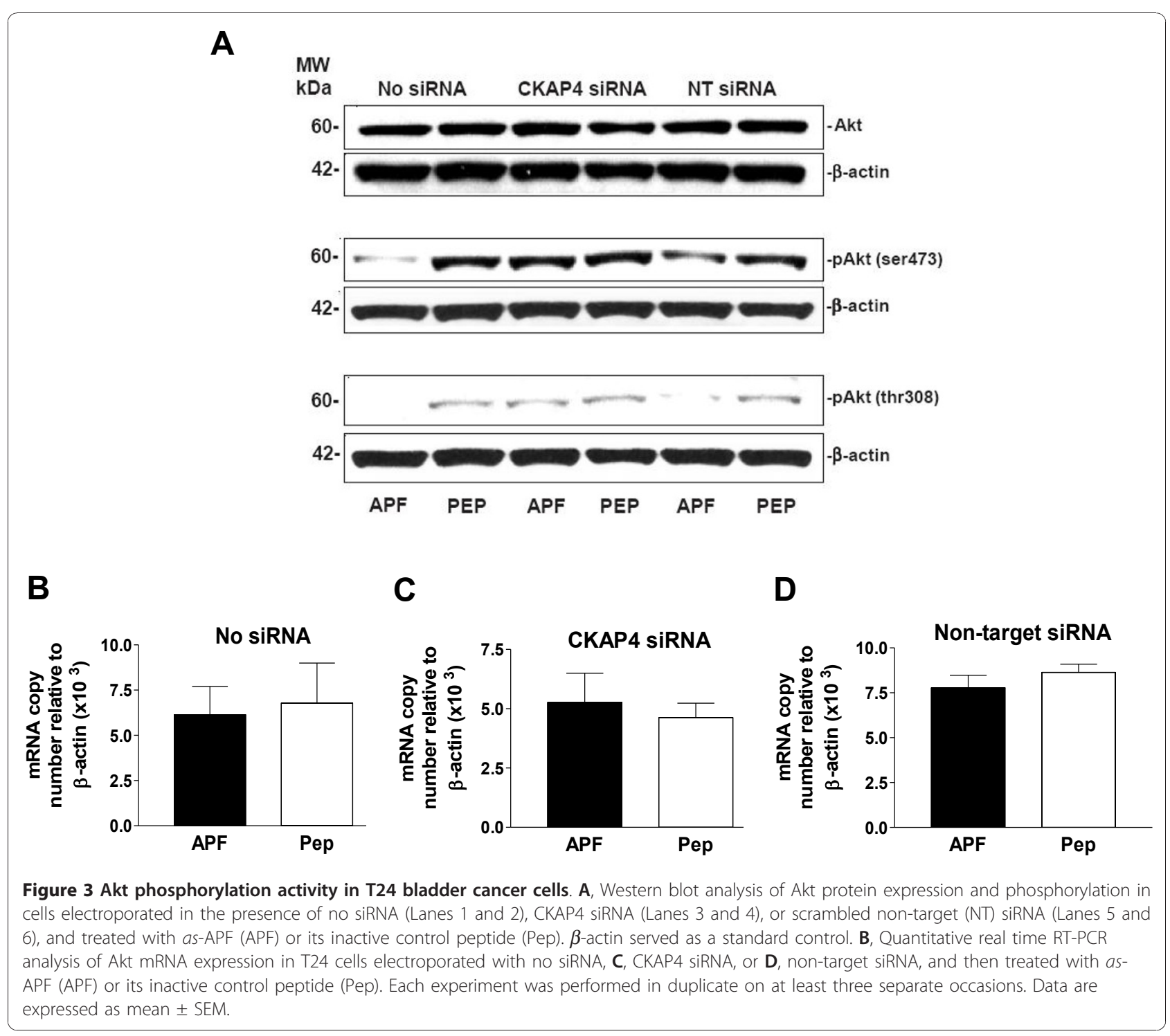

be stimulated by HB-EGF in carcinoma cells [38], we next determined whether as-APF also regulated MMP2 expression in T24 cells.

As shown in Figure 6A, APF treatment decreased MMP2 protein expression in nontransfected or non-target siRNA-transfected, but not CKAP4 siRNA-transfected, T24 cells. Similarly, APF treatment resulted in significantly decreased MMP2 mRNA levels in nontransfected or nontarget transfected but not CKAP4 siRNA-transfected cells (Figure 6B-D) ( $<<.01$ for nontransfected and $\mathrm{p}<.05$ for non-target transfected cells, regardless of whether target gene mRNA expression was calculated relative to $\beta$-actin or GAPDH mRNA; data shown for normalization to $\beta$-actin expression, only). These findings indicate that APF inhibits MMP2 mRNA and protein expression in T24 cells via CKAP4.

\section{Discussion}

The current study shows that APF mediates its antiproliferative effects in T24 bladder carcinoma cells via the CKAP4 transmembrane receptor, as found previously for normal bladder epithelial cells [27]. Further, it indicates that the mechanism whereby APF inhibits bladder carcinoma cell proliferation via CKAP4 involves the regulation of phosphorylation (with activation or inactivation) of various cell signaling molecules including Akt, GSK $3 \beta, \beta$-catenin, along with mRNA and protein expression of p53 and MMP2.

CKAP4, which was first described as a reversibly palmitoylated type II transmembrane receptor [28], was previously shown to bind the synthetic form of a natural bladder epithelial cell antiproliferative factor (as-APF) and mediate its effects on normal bladder epithelial cell 


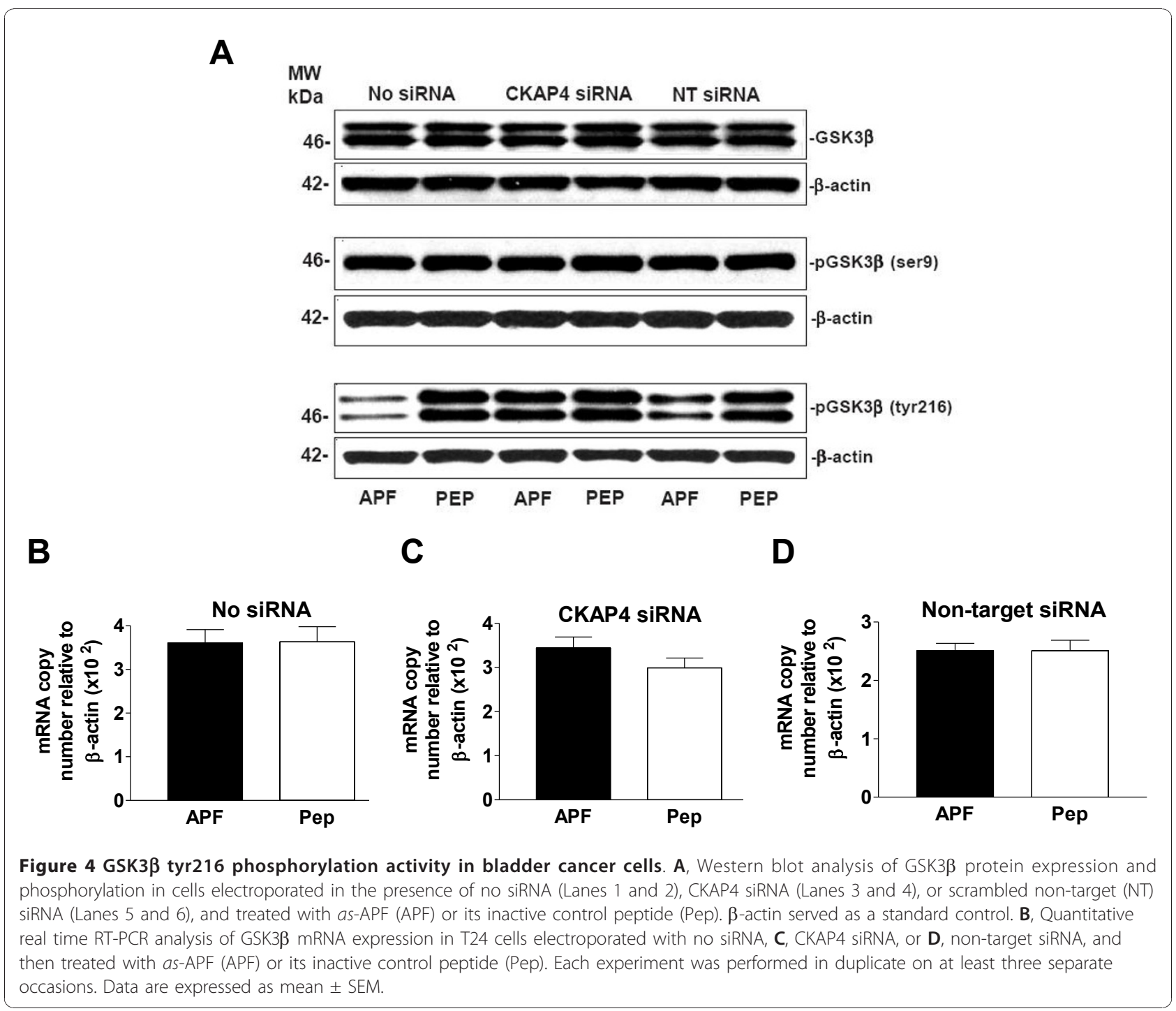

proliferation [27]. Results from the current study show that the CKAP4 receptor is also required for inhibition of bladder carcinoma cell proliferation by as-APF in vitro. In addition, experiments performed to elucidate the mechanism of APF activity indicate that this frizzled 8-related glycopeptide induces altered expression or phosphorylation of certain proteins that differ in some aspects from those seen in canonical Wnt/frizzled signaling.

Downstream signal transducers for Wnt/frizzled signaling include Akt, GSK3 $\beta$, and $\beta$-catenin [39]. The serine threonine kinase Akt, also known as protein kinase $\mathrm{B}(\mathrm{PKB})$, is a central regulator of cell proliferation, motility and survival whose activity is often altered in human malignancies [40]. Akt mediates its downstream effects via phosphorylation/inactivation of GSK3 $\beta$ ser9, with subsequently decreased phosphorylation of the GSK3 $\beta$ target $\beta$-catenin, resulting in increased $\beta$-catenin nuclear translocation, binding to T-cell factor, and stimulation of gene expression related to cell proliferation and survival $[30,41]$. In addition to its association with malignant cell proliferation, increased Akt phosphorylation/activation has also been linked to the invasive properties of bladder cancer cells [40]. The inhibition of Akt ser473 and thr308 phosphorylation by APF suggests that APF may profoundly inhibit bladder epithelial cell Akt activity, and therefore decrease bladder carcinoma cell invasive potential, as well.

GSK3 $\beta$ activity is reduced by phosphorylation of ser9 but stimulated by phosphorylation on tyr216 [42], and the downstream effects of Akt activation/phosphorylation during Wnt/frizzled signaling include increased ser9 phosphorylation with decreased activity of GSK $3 \beta$, decreased GSK3 $\beta$-induced $\beta$-catenin ser33,37 phosphorylation, and subsequently decreased $\beta$-catenin ubiquitination and degradation. If as-APF mediated its activity in 
A
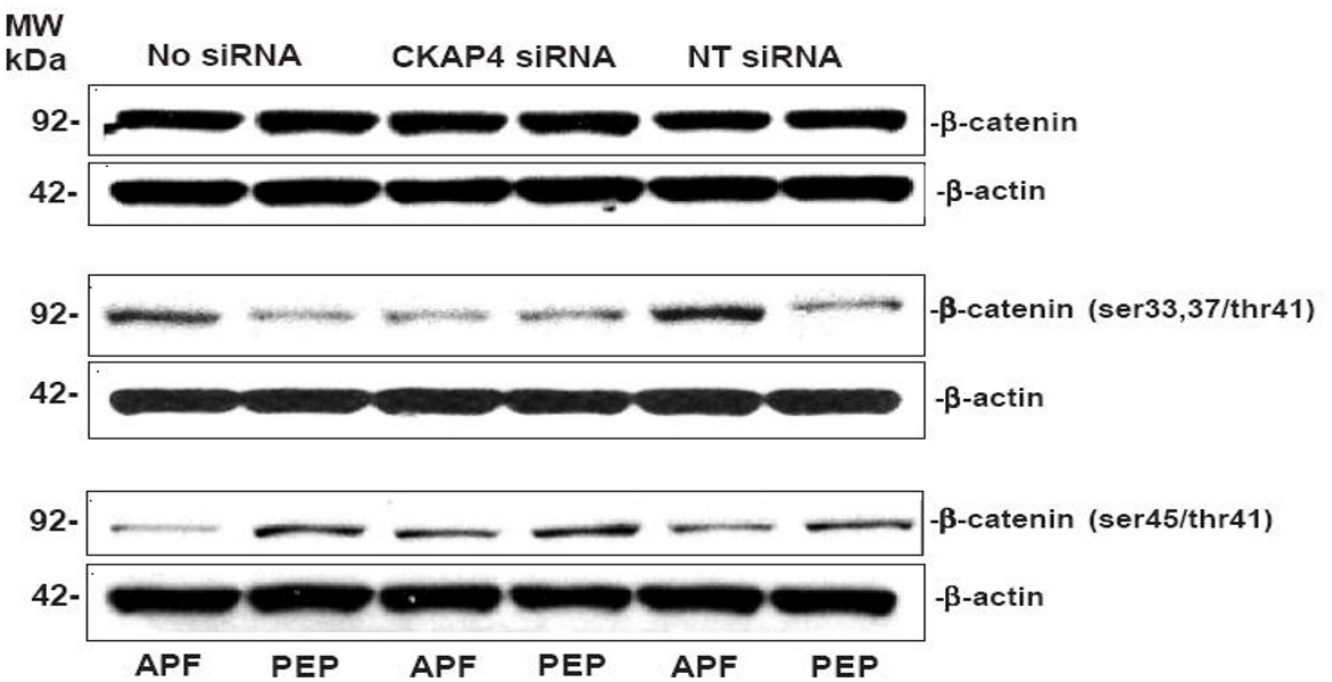

B

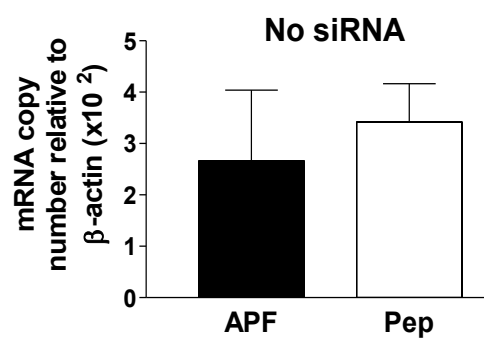

C

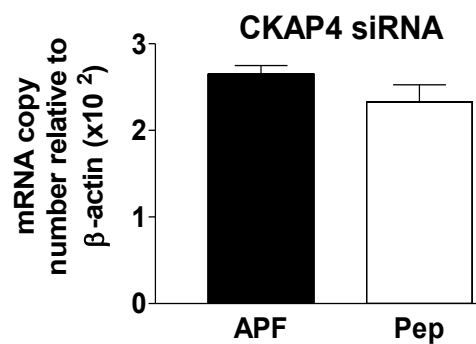

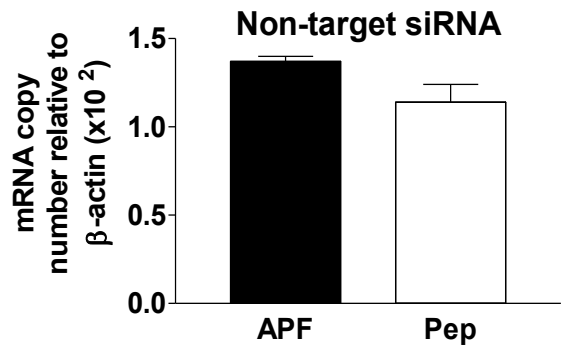

Non-target siRNA APF

Pep

Figure $5 \boldsymbol{\beta}$-catenin phosphorylation in T24 bladder cancer cells. A, Western blot analysis of $\beta$-catenin protein expression and phosphorylation activity in cells electroporated in the presence of no siRNA (Lanes 1 and 2), CKAP4 siRNA (Lanes 3 and 4), or scrambled nontarget (NT) siRNA (Lanes 5 and 6), and treated with as-APF (APF) or its inactive control peptide (Pep). $\beta$-actin served as a standard control. B, Quantitative real time RT-PCR analysis of $\beta$-catenin mRNA expression in T24 cells electroporated with no siRNA, C, CKAP4 siRNA, or D, non-target siRNA, and then treated with as-APF (APF) or its inactive control peptide (Pep). Each experiment was performed in duplicate on at least three separate occasions. Data are expressed as mean \pm SEM.

T24 cells purely by inhibiting canonical Wnt/frizzled signaling (like other secreted frizzled-related cell growth inhibitors), GSK3 $\beta$ ser9 phosphorylation should have been decreased substantially, while tyr216 phosphorylation (which may be mediated by mitogen-activated protein kinase kinase (MEK) 1/2) [43] should not have been affected. Our results, which showed only a very minimal decrease in GSK3 3 ser9 phosphorylation, but a substantial decrease in GSK3 $\beta$ yr216 phosphorylation, indicate that as-APF: 1) does not mediate its activity purely by regulating Wnt/frizzled canonical signaling; 2) may inhibit GSK3 $\beta$ and additional kinases (such as MEK 1/2); and 3) may mediate its antiproliferative effects in T24 cells via inhibition of Akt, GSK3 $\beta$, and/or MEK1/2 involving downstream effects on targets in addition to $\beta$-catenin. Indeed, the modest increase in apparent phosphorylation of $\beta$-catenin ser33,37/thr41, along with a decrease in phosphorylation of $\beta$-catenin ser 45 (which is mediated by autophosphorylation, casein kinase 1 , and/or a complex of cyclin D1/cyclin-dependent kinase 6, and which primes ser33,37 for phosphorylation by GSK3 $\beta$ ) $[42,44]$, suggests that the regulation of total $\beta$-catenin protein and/or inhibition of canonical Wnt/ frizzled signaling may not be the sole mechanism by which APF induces its effects on cell proliferation and gene expression.

Matrix metalloproteinases (MMPs) are a multigene family of zinc-dependent endopeptidases that degrade extracellular matrix components, whose expression is also regulated via Wnt/frizzled signaling pathways 


\section{A}

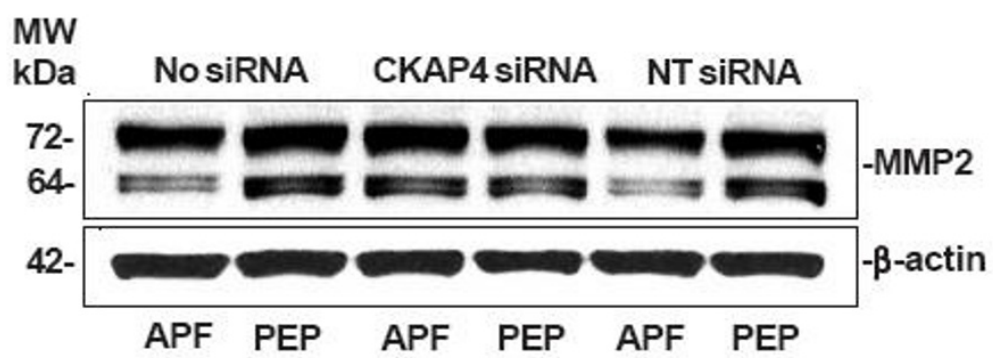

B
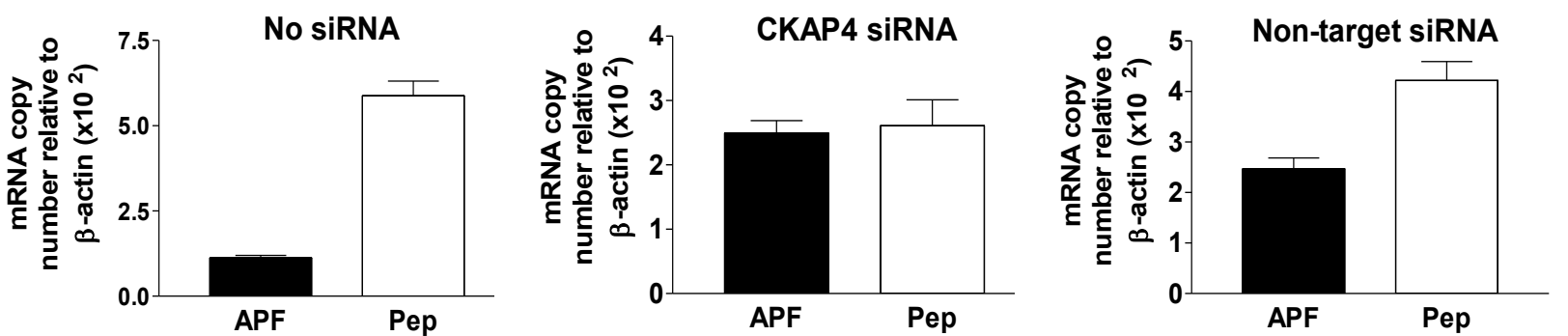

Figure 6 MMP2 expression in T24 bladder cancer cells. A, Western blot analysis of MMP2 protein expression in cells electroporated in the presence of no siRNA (Lanes 1 and 2), CKAP4 siRNA (Lanes 3 and 4), or scrambled non-target (NT) siRNA (Lanes 5 and 6), and treated with asAPF (APF) or its inactive control peptide (Pep). $\beta$-actin served as a standard control. B, Quantitative real time RT-PCR analysis of MMP2 mRNA expression in T24 cells electroporated with no siRNA, C, CKAP4 siRNA, or D, non-target siRNA, and then treated with as-APF (APF) or its inactive control peptide (Pep). Each experiment was performed in duplicate on at least three separate occasions. Data are expressed as mean \pm SEM.

$[31,32]$ and has been shown to correlate with invasive potential of many different tumors [45]. Expression of MMP2 is associated with bladder carcinoma cell invasion and metastasis [34-37]. The ability of as-APF to significantly inhibit MMP2 mRNA and protein expression in T24 cells also suggests that as-APF may be able to decrease the invasive potential of bladder carcinoma cells as well as inhibit their proliferation.

Previous experiments performed by Jayoung Kim showed that p53 mediated the antiproliferative effects of native APF in both normal and T24 bladder carcinoma cells [22]. The current study confirms this result by showing that synthetic as-APF also increases p53 protein and mRNA expression in T24 cells, and it further demonstrates the role of the CKAP4 receptor in APFinduced p53 upregulation.

Although the expression or activation of each of the cell proteins shown to be modified by APF can be regulated via $\mathrm{Wnt} /$ frizzled pathways, the specific alterations seen in Akt/GSK3 $\beta / \beta$-catenin phosphorylation and the lack of an effect of APF on total cellular $\beta$-catenin levels suggest that this secreted frizzled-related peptide does not inhibit T24 bladder cell proliferation solely via inhibition of canonical Wnt/frizzled signaling. Whether the CKAP4 receptor can mediate transmembrane signaling, and/or whether it functions as a chaperone protein for cytoplasmic or nuclear translocation of APF, is unknown [27,29]. However, the myriad effects of APF on cell protein activation and expression discovered in the current as well as previous studies $[19,21]$ indicate it may inhibit cell proliferation by regulating the activity of more than one signaling pathway or transcriptional regulatory factor.

The ability of as-APF to inhibit GSK3 $\beta$ tyr216 phosphorylation without inhibiting GSK3 $\beta$ ser9 phosphorylation suggests it may also be a potent GSK3 $\beta$ enzyme inhibitor in T24 cells. Recent studies on natural compound GSK3 $\beta$ inhibitors suggest that this class of drugs may be promising for the regulation of certain cancers [46]. Additional in vitro and in vivo studies with this intriguing natural frizzled 8-related glycopeptide are in progress to elucidate further its important cell regulatory function(s) as well as its potential as a therapeutic agent.

\section{Abbreviations}

APF: antiproliferative factor; as-APF: asialo-APF; CKAP4: cytoskeletonassociated protein 4; IC: interstitial cystitis; FBS: fetal bovine serum; qRT-PCR: quantitative reverse transcriptase polymerase chain reaction; $\mathrm{Rb}$ : retinoblastoma gene; HB-EGF: heparin-binding epidermal growth factor-like growth factor; siRNA: small interfering ribonucleic acid; MMP: matrix 
metalloproteinase; GSK: glycogen synthase kinase; Wnt: wingless-int; Akt: AKR-transforming enzyme; NT: non-target; GAPDH: glyceraldehyde phosphate dehydrogenase; ser: serine; tyr: tyrosine; thr: threonine; siRNA: small interfering RNA

\section{Acknowledgements}

The authors thank Eunice Katz for her assistance with the preparation of this manuscript. This material is based upon work supported by the Office of Research and Development (Medical Research Service), Department of Veterans Affairs.

\section{Author details}

'Division of Infectious Diseases, Department of Medicine, University of Maryland School of Medicine, Baltimore, Maryland, USA. ${ }^{2}$ Staff physician, Medical Service, Department of Veterans Affairs Medical Center, Baltimore, Maryland, USA.

\section{Authors' contributions}

HMS carried out major experiments for these studies. KRK and COZ performed some of the GRT-PCR, and LG and COZ performed some of the Western blots, for this paper. SKK supervised the research and interpretation of the data. HMS and SKK also prepared the manuscript, which was reviewed by the other authors prior to submission.

\section{Competing interests}

SKK is named as an inventor on a patent for APF and a patent application that includes synthetic as-APF.

Received: 8 October 2010 Accepted: 10 December 2010 Published: 10 December 2010

\section{References}

1. Jemal A, Siegel R, Ward E, Murray T, Xu J, Thun MJ: Cancer statistics, 2007. CA Cancer J Clin 2007, 57:43-66.

2. Kaufman DS, Shipley WU, Feldman AS: Bladder cancer. Lancet 2009, 74:239-249.

3. Sonpavde G, Sternberg CN: Treatment of metastatic urothelial cancer: opportunities for drug discovery and development. BJU Int 2008, 102:1354-1360.

4. Lipponen PK, Eskelinen MJ: Reduced expression of E-cadherin is related to invasive disease and frequent recurrence in bladder cancer. $J$ Cancer Res Clin Oncol 1995, 121:303-308.

5. Syrigos KN, Krausz T, Waxman J, Pandha H, Rowlinson-Busza G, Verne J, Epenetos AA, Pignatelli M: E-cadherin expression in bladder cancer using formalin-fixed, paraffin-embedded tissues: correlation with histopathological grade, tumour stage and survival. Int J Cancer 1995, 64:367-370,

6. Wakatsuki S, Watanabe R, Saito K, Saito T, Katagiri A, Sato S, Tomita Y: Loss of human E-cadherin (ECD) correlated with invasiveness of transitional cell cancer in renal pelvis, ureter and urinary bladder. Cancer Lett 1996, 103:11-17.

7. Erdemir F, Ozcan F, Kilicaslan I, Parlaktas BS, Uluocak N, Gokce O: The relationship between the expression of E-cadherin and tumor recurrence and progression in high-grade stage $\mathrm{T} 1$ bladder urothelial carcinoma. Int Urol Nephrol 2007, 39:1031-1037.

8. Otto T, Birchmeier W, Schmidt U, Hinke A, Schipper J, Rübben H, Raz A: Inverse relation of E-cadherin and autocrine motility factor receptor expression as a prognostic factor in patients with bladder carcinomas. Cancer Res 1994, 54:3120-3123.

9. Slaton JW, Benedict WF, Dinney CP: p53 in bladder cancer: mechanism of action, prognostic value, and target for therapy. Urology 2001, 57:852-859.

10. Nishiyama $\mathrm{H}$, Watanabe J, Ogawa O: p53 and chemosensitivity in bladder cancer. Int J Clin Oncol 2008, 13:282-286.

11. Stein JP, Ginsberg DA, Grossfeld GD, Chatterjee SJ, Esrig D, Dickinson MG, Groshen S, Taylor CR, Jones PA, Skinner DG, Cote RJ: Effect of p21 WAF1/CIP1 expression on tumor progression in bladder cancer. J Natl Cancer Instit 1998, 90:1072-1079.

12. Thøgersen VB, Sørensen BS, Poulsen SS, Orntoft TF, Wolf H, Nexo E: A subclass of HER1 ligands are prognostic markers for survival in bladder cancer patients. Cancer Res 2001, 61:6227-6233.
13. Schäfer B, Gschwind A, Ullrich A: Multiple G-protein-coupled receptor signals converge on the epidermal growth factor receptor to promote migration and invasion. Oncogene 2004, 23:991-999.

14. Ongusaha PP, Kwak JC, Zwible AJ, Macip S, Higashiyama S, Taniguchi N, Fang L, Lee SW: HB-EGF is a potent inducer of tumor growth and angiogenesis. Cancer Res 2004, 64:5283-5290.

15. Adam RM, Danciu T, McLellan DL, Borer JG, Lin J, Zurakowski D, Weinstein MH, Rajjayabun PH, Mellon JK, Freeman MR: A nuclear form of the heparin-binding epidermal growth factor-like growth factor precursor is a feature of aggressive transitional cell carcinoma. Cancer Res 2003, 63:484-490.

16. Keay S, Zhang C-O, Hise M, Trifillis AL, Hebel JR, Jacobs SC, Warren JW: Decreased ${ }^{3} \mathrm{H}$-thymidine incorporation by human bladder epithelial cells following exposure to urine from interstitial cystitis patients. J Urol 1996, 156:2073-2078.

17. Keay S, Kleinberg M, Zhang C-O, Hise MK, Warren JW: Bladder epithelial cells from interstitial cystitis patients produce an inhibitor of HB-EGF production. J Urol 2000, 164:2112-2118.

18. Keay S, Warren JW, Zhang C-O, Tu LM, Gordon DA, Whitmore KE: Antiproliferative activity is present in bladder but not renal pelvic urine from interstitial cystitis patients. J Urol 1999, 162:1487-1489.

19. Keay SK, Szekely Z, Conrads TP, Veenstra TD, Barchi JJ Jr, Zhang CO, Koch KR, Michejda CJ: An antiproliferative factor from interstitial cystitis patients is a frizzled 8 protein-related sialoglycopeptide. Proc Natl Acad Sci USA 2004, 101:11803-11808.

20. Keay S, Zhang C-O, Shoenfelt JL, Chai TC: Decreased in vitro proliferation of bladder epithelial cells from patients with interstitial cystitis. Urology 2003, 61:1278-1284.

21. Keay S, Seillier-Moiseiwitsch F, Zhang C-O, Chai TC, Zhang J: Changes in human bladder cell gene expression associated with interstitial cystitis or antiproliferative factor treatment. Physiol Genomics 2003, 14:107-115.

22. Kim J, Keay SK, Dimitrakov JD, Freeman MR: p53 mediates interstitial cystitis antiproliferative factor (APF)-induced growth inhibition of human urothelial cells. FEBS Lett 2007, 581:3795-3799.

23. Zhang C-O, Wang JY, Koch KR, Keay S: Regulation of tight junction proteins and bladder epithelial paracellular permeability by an antiproliferative factor from patients with interstitial cystitis. J Urol 2005 174:2382-2387.

24. Johansson SL, Fall M: Clinical features and spectrum of light microscopic changes in interstitial cystitis. J Urol 1990, 143:1118-1124.

25. Skoluda D, Wegner K, Lemmel EM: Critical Notes: Respective immune pathogenesis of interstitial cystitis (article in German). Urologe A 1974, 13:15-23.

26. Tomaszewski JE, Landis JR, Russack V, Williams TM, Wang LP, Hardy C, Brensinger C, Matthews YL, Abele ST, Kusek JW, Nyberg LM, Interstitia Cystitis Database Study Group: Biopsy features are associated with primary symptoms in interstitial cystitis: results from the Interstitial Cystitis Database Study Group. Urology 2001, 57:67-81.

27. Conrads TP, Tocci GM, Hood BL, Zhang CO, Guo L, Koch KR, Michejda CJ, Veenstra TD, Keay SK: CKAP4 is a receptor for the frizzled-8 proteinrelated antiproliferative factor from interstitial cystitis patients. J Biol Chem 2006, 281:37836-37843.

28. Schweizer A, Ericsson M, Bächi T, Griffiths G, Hauri HP: Characterization of a novel $63 \mathrm{kDa}$ membrane protein. Implications for the organization of the ER-to-Golgi pathway. J Cell Sci 1993, 104:671-683.

29. Planey SL, Keay SK, Zhang C-O, Zacharias DA: Palmitoylation of cytoskeleton associated protein 4 by $\mathrm{DHHC2}$ regulates antiproliferative factor-mediated signaling. Mol Biol Cell 2009, 20:1454-1463.

30. Widelitz R: Wnt signaling through canonical and non-canonical pathways: recent progress. Growth Factors 2005, 23:111-116.

31. Zi X, Guo Y, Simoneau AR, Hope C, Xie J, Holcombe RF, Hoang BH: Expression of Frzb/secreted Frizzled-related protein 3, a secreted Wnt antagonist, in human androgen-independent prostate cancer PC-3 cells suppresses tumor growth and cellular invasiveness. Cancer Res 2005, 65:9762-9770.

32. Wu B, Crampton SP, Hughes CC: Wnt signaling induces matrix metalloproteinase expression and regulates $\mathrm{T}$ cell transmigration. Immunity 2007, 26:227-239.

33. Roelle $\mathrm{S}$, Grosse R, Aigner A, Krell HW, Czubayko F, Gudermann T: Matrix metalloproteinases 2 and 9 mediate epidermal growth factor receptor 
transactivation by gonadotropin-releasing hormone. J Biol Chem 2003, 278:47307-47318.

34. Kanayama H: Matrix metalloproteinases and bladder cancer. J Med Invest 2001, 48:31-43.

35. Gerhards S, Jung K, Koenig F, Daniltchenko D, Hauptmann S, Schnorr D, Loening SA: Excretion of matrix metalloproteinases 2 and 9 in urine is associated with a high stage and grade of bladder carcinoma. Urology 2001, 57:675-679.

36. Moses MA, Wiederschain D, Loughlin KR, Zurakowski D, Lamb CC Freeman MR: Increased incidence of matrix metalloproteinases in urine of cancer patients. Cancer Res 1998, 58:1395-1399.

37. Papathoma AS, Petraki C, Grigorakis A, Papakonstantinou H, Karavana V, Stefanakis S, Sotsiou F, Pintzas A: Prognostic significance of matrix metalloproteinases 2 and 9 in bladder cancer. Anticancer Res 2000, 20:2009-2013.

38. Yagi $H$, Yotsumoto F, Miyamoto S: Heparin-binding epidermal growth factor-like growth factor promotes transcoelomic metastasis in ovarian cancer through epithelial-mesenchymal transition. Mol Cancer Ther 2008, 7:3441.

39. Li F, Chong ZZ, Maiese K: Winding through the WNT pathway during cellular development and demise. Histol Histopathol 2006, 21:103-124.

40. Wu X, Obata T, Khan Q, Highshaw RA, DeVere White R, Sweeney C: The phosphatidylinositol-3 kinase pathway regulates bladder cancer cell invasion. BJU Int 2004, 93:143-50

41. Cheng JQ, Lindsley CW, Cheng GZ, Yang H, Nicosia SV: The Akt/PKB pathway: molecular target for cancer drug discovery. Oncogene 2005, 24:7482-7492.

42. Wang QM, Fiol CJ, DePaoli-Roach AA, Roach PJ: Glycogen synthase kinase3 beta is a dual specificity kinase differentially regulated by tyrosine and serine/threonine phosphorylation. J Biol Chem 1994, 269:14566-14574.

43. Takahashi-Yanaga F, Shiraishi F, Hirata M, Miwa Y, Morimoto S, Sasaguri T: Glycogen synthase kinase-3beta is tyrosine-phosphorylated by MEK1 in human skin fibroblasts. Biochem Biophys Res Commun 2004, 316:411-415.

44. Hagen T, Vidal-Puig A: Characterisation of the phosphorylation of betacatenin at the GSK-3 priming site Ser45. Biochem Biophys Res Commun 2002, 294:324-328

45. Stetler-Stevenson WG: Metalloproteinases and cancer invasion. Semin Cancer Biol 1990, 1:99-106.

46. Gaisina IN, Gallier F, Ougolkov AV, Kim KH, Kurome T, Guo S, Holzle D, Luchini DN, Blond SY, Billadeau DD, Kozikowski AP: From a natural product lead to the identification of potent and selective benzofuran-3-yl-(indol3 -yl) maleimides as glycogen synthase kinase 3 beta inhibitors that suppress proliferation and survival of pancreatic cancer cells. J Med Chem 2009, 52:1853-1863.

\section{doi:10.1186/1756-9966-29-160}

Cite this article as: Shahjee et al: Antiproliferative factor decreases Akt phosphorylation and alters gene expression via CKAP4 in T24 bladder carcinoma cells. Journal of Experimental \& Clinical Cancer Research 2010 29:160.

\section{Submit your next manuscript to BioMed Central and take full advantage of:}

- Convenient online submission

- Thorough peer review

- No space constraints or color figure charges

- Immediate publication on acceptance

- Inclusion in PubMed, CAS, Scopus and Google Scholar

- Research which is freely available for redistribution 